NOTICE: this is the author's version of a work that was accepted for publication in Tetrahedron Letters. Changes resulting from the publishing process, such as peer review, editing, corrections, structural formatting, and other quality control mechanisms may not be reflected in this document. Changes may have been made to this work since it was submitted for publication. A definitive version was subsequently published in Tetrahedron Letters, $50,18,2009$. DOI 10.1016.j.tetlet.2009.02.172 


\section{Graphical Abstract}

An aqueous medium synthesis and
tautomerism study of 3(5)-amino-1,2,4-
triazoles
Anton V. Dolzhenko, Giorgia Pastorin,
Anna V. Dolzhenko and Wai Keung Chui




\title{
An aqueous medium synthesis and tautomerism study of 3(5)-amino-1,2,4-triazoles
}

\author{
Anton V. Dolzhenko, Giorgia Pastorin, Anna V. Dolzhenko and Wai Keung Chui \\ Department of Pharmacy, Faculty of Science, National University of Singapore, 18 Science Drive 4, Singapore 117543, Singapore
}

\begin{abstract}
A catalyst-free highly efficient synthesis of 3(5)-amino-5(3)-(het)aryl-1,2,4-triazoles in aqueous medium was performed using conventional heating and microwave irradiation. The tautomerism in the products was investigated using NMR spectroscopy and X-ray crystallography. The effects of the substitution, temperature, solvents and concentration on the tautomerism were studied. The triazoles were found to exist in $1 H$-forms, the $4 H$-form was not observed either in solid state or in solution. In general, 5-amino-1,2,4-triazoles were electronically preferred in the tautomeric equilibrium, but some exceptions from the established relationship were also identified. (C) 2011 Elsevier Science. All rights reserved
\end{abstract}

1,2,4-Triazoles represent a class of heterocyclic compounds of significant importance in agriculture and medicine. ${ }^{1}$ They are also used in metalloorganic chemistry as polyfunctional ligands. ${ }^{2}$ Among 1,2,4-triazoles, 3(5)amino-1,2,4-triazoles have been recognized, primarily, as valuable synthons for the construction of more complex structures, particularly biologically active fused heterocycles (e.g. 1,2,4-triazolo[1,5-a]pyrimidines ${ }^{3}$ and

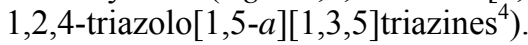

The most straightforward and commonly used method for the preparation of 3(5)-amino-1,2,4-triazoles 2 involves the cyclocondensation of amidoguanidines 1 (Scheme 1). However, the use of a high temperature (often above the melting point $)^{5}$ or the presence of a strong base ${ }^{5 \mathrm{e}}$ in the reaction complicated the workup and led to decreased yields of the products. Herein we describe a method which avoids these drawbacks and leads to 3(5)-amino-1,2,4triazoles via a simple and eco-friendly procedure.

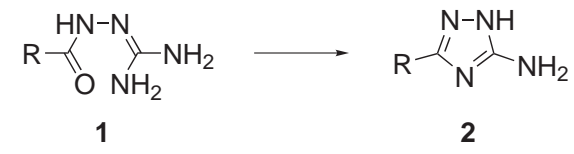

Scheme 1
Tautomerism in five-membered heterocyclic systems is an intriguing phenomenon, which has been well recognized for a long time. ${ }^{6}$ A knowledge of the tautomeric preferences and the factors affecting the equilibrium is essential for understanding the reactivity of compounds in chemical processes and their effects on biological systems. Due to annular prototropic tautomerism, 1,2,4-triazoles, particularly amino-1,2,4-triazoles without substituents on the ring nitrogen atoms, a priori can exist in three forms, viz 3-amino-1H-1,2,4-triazoles (A), 5-amino- $1 H$-1,2,4triazoles (B) and 3-amino-4H-1,2,4-triazoles (C) (Scheme 2). A number of theoretical reports ${ }^{7}$ have appeared in the area of tautomerism in amino-1,2,4-triazoles, but experimental studies have often ignored this phenomenon and some data were misinterpreted. In this Letter, we present a study on the tautomerism in 3(5)-amino-5(3)(het)aryl-1,2,4-triazoles using NMR spectroscopy and Xray crystallography.

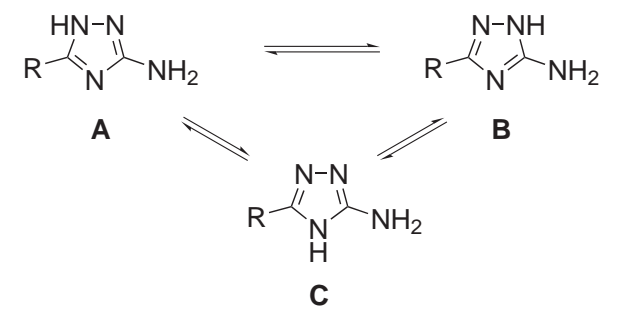

Scheme 2 .

\footnotetext{
* Corresponding author. Tel.: (65) 6516 2657; fax: (65) 6779 1554; e-mail: phada@nus.edu.sg.
} 
Table 1. Synthesis of triazoles 2a-j via cyclocondensation of amidoguanidines 1 under conventional heating

$$
\underset{\mathrm{O}}{\stackrel{\mathrm{NN}}{\mathrm{HN}} \mathrm{NH}_{2}} \longrightarrow
$$

1

\begin{tabular}{|c|c|c|c|c|c|}
\hline Triazole & $\mathrm{R}$ & $\begin{array}{l}\text { Reaction } \\
\text { time, } \mathrm{h}\end{array}$ & $\begin{array}{l}\text { Volume, } \\
\mathrm{ml}^{\text {a }}\end{array}$ & $\begin{array}{l}\text { Yield, } \\
\%\end{array}$ & $\mathrm{mp},{ }^{\circ} \mathrm{C}$ (lit) \\
\hline $2 a$ & $\mathrm{Ph}$ & 4 & 20 & 97 & $\begin{array}{l}186-187 \\
(186-187)^{5 \mathrm{e}}\end{array}$ \\
\hline $2 \mathbf{b}$ & 4- $\mathrm{MeC}_{6} \mathrm{H}_{4}$ & 4 & 20 & 98 & $\begin{array}{l}209 \\
(207)^{8 a}\end{array}$ \\
\hline $2 c$ & $4-\mathrm{MeOC}_{6} \mathrm{H}_{4}$ & 8 & 40 & 96 & $\begin{array}{l}226 \\
(224-226)^{5 e}\end{array}$ \\
\hline $2 d$ & 4- $\mathrm{FC}_{6} \mathrm{H}_{4}$ & 3 & 20 & 95 & 188-189 \\
\hline $2 e$ & 4- $\mathrm{ClC}_{6} \mathrm{H}_{4}$ & 6 & $60^{\mathrm{b}}$ & 94 & $\begin{array}{l}229-230 \\
(227-229)^{5 e}\end{array}$ \\
\hline $2 f$ & 2 -furyl & 6 & 20 & 95 & $\begin{array}{l}211-212 \\
(204-206)^{8 b}\end{array}$ \\
\hline $2 \mathrm{~g}$ & 2-thienyl & 8 & 30 & 97 & 214 \\
\hline $2 h$ & 2-pyridyl & 4 & 20 & 92 & $\begin{array}{l}220-221 \\
(217)^{8 \mathrm{c}}\end{array}$ \\
\hline $2 \mathbf{i}$ & 3-pyridyl & 6 & 20 & 98 & $\begin{array}{l}224-225 \\
(223)^{8 c}\end{array}$ \\
\hline $2 \mathbf{j}$ & 4-pyridyl & 6 & 20 & 98 & $\begin{array}{l}272-274 \\
(276-278)^{5 d}\end{array}$ \\
\hline
\end{tabular}

${ }^{\mathrm{a}}$ Volume of water per $1 \mathrm{~g}$ of $\mathbf{1}$.

${ }^{\mathrm{b}} 40 \%$ ethanol was used as solvent.

Green chemistry, which is an essential part of process development in modern chemistry, has also begun to influence medicinal chemistry significantly. ${ }^{9}$ The design of an environmentally friendly synthesis includes elaboration of methods able to avoid or minimize the formation of byproducts, the selection of a safe solvent and effective use of energy. Water is considered to be the best solvent for sustainable chemistry. ${ }^{10}$ We found that (het)arylamidoguanidines (1), upon heating in water, underwent quantitative cyclocondensation with elimination of a water molecule affording 3(5)-amino-5(3)-(het)aryl1,2,4-triazoles (2) (Table 1). ${ }^{11}$ The reaction provided the products in excellent purity and did not require the presence of base or catalyst. The solubility of the starting (het)arylamidoguanidines $\mathbf{1}$ was found to be a limiting factor of the reaction and increasing the volume of water or using a co-solvent (ethanol) were required for some less soluble amidoguanidines 1. However, when ethanol was used as the sole solvent instead of water, the conversion of $1 \mathbf{a}$ into 3(5)-amino-5(3)-phenyl-1,2,4-triazole (2a) did not proceed to the completion even after 3 days of heating under reflux.

Microwave irradiation is an alternative source of energy, which allows highly effective use of the heat produced, reducing reaction times and often improving yields. Microwave-assisted syntheses have found extensive applications in heterocyclic chemistry, ${ }^{12}$ and a number of methods for the preparation of 1,2,4-triazoles using microwave irradiation have been reported. ${ }^{13}$ However, no data on microwave-based syntheses of 3(5)-amino-1,2,4triazoles are available. Since water is an excellent solvent for microwave-assisted reactions, ${ }^{14}$ and provided it is a suitable medium for cyclocondensation of $\mathbf{1}$ under conventional heating, we attempted to use it as a solvent in the microwave-initiated synthesis. Four regimes with fixed microwave irradiation power were applied using a CEM "Discover" apparatus and $100 \mathrm{~W}$ was found to be optimal microwave power for the cyclization of 1a (Table 2). ${ }^{15}$ These conditions were then applied successfully for the preparation of other 3(5)-amino-5(3)-(het)aryl-1,2,4triazoles (2) (Table 3). We attempted to prepare 2a by heating 1a in ethanol using similar irradiation conditions. However, a longer reaction time $(5 \mathrm{~min})$ was required and the isolated yield was lower $(86 \%)$.

The structures of the compounds prepared and particularly their tautomerism were investigated using both NMR spectroscopy, which is considered to be the most informative and accurate method for solutions, ${ }^{16}$ and X-ray crystallography, which provides comprehensive structural information in solid state. ${ }^{16 b, c}$

Table 2. Optimization of the microwave-assisted synthesis of 2a

\begin{tabular}{|c|c|c|}
\hline$\overbrace{1}^{\mathrm{PN}-\mathrm{N}}$ & $\mathrm{H}_{2}$ & $\begin{array}{l}\mathrm{N}-\mathrm{NH} \\
\mathbf{2 a}\end{array}$ \\
\hline Microwave power, W & Reaction time, sec & Yield, $\%$ \\
\hline 50 & 420 & 94 \\
\hline 100 & 150 & 100 \\
\hline 150 & 120 & 88 \\
\hline 200 & 70 & 82 \\
\hline
\end{tabular}

Table 3. Microwave-assisted synthesis of triazoles $\mathbf{2 a - j}$ in water, $100 \mathrm{~W}$

\begin{tabular}{|c|c|c|c|}
\hline & $\overbrace{1}^{\mathrm{HN}-\mathrm{N}} \underset{\mathrm{NH}_{2}}{\mathrm{~N}}$ & $\mathrm{R}-\mathrm{N}_{N}^{\mathrm{N}-}$ & $\mathrm{NH}_{2}$ \\
\hline Triazole & $\mathrm{R}$ & Reaction time, sec & Yield, \% \\
\hline $2 a$ & $\mathrm{Ph}$ & 150 & 100 \\
\hline $2 b$ & 4- $\mathrm{MeC}_{6} \mathrm{H}_{4}$ & 165 & 100 \\
\hline 2c & $4-\mathrm{MeOC}_{6} \mathrm{H}_{4}$ & 165 & 100 \\
\hline 2d & 4- $\mathrm{FC}_{6} \mathrm{H}_{4}$ & 150 & 90 \\
\hline $2 \mathbf{e}$ & 4- $\mathrm{ClC}_{6} \mathrm{H}_{4}$ & 180 & 100 \\
\hline $2 f$ & 2-furyl & 165 & 100 \\
\hline $2 g$ & 2-thienyl & 180 & 100 \\
\hline $2 \mathbf{h}$ & 2-pyridyl & 150 & 84 \\
\hline $2 \mathbf{i}$ & 3-pyridyl & 150 & 100 \\
\hline $2 \mathbf{j}$ & 4-pyridyl & 150 & 88 \\
\hline
\end{tabular}


Table 4. Tautomerism in 3(5)-amino-1,2,4-triazoles in DMSO- $d_{6}$ solution

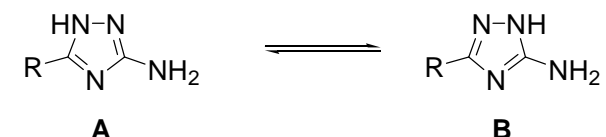

\begin{tabular}{|c|c|c|c|c|c|c|c|}
\hline \multirow[t]{3}{*}{ Triazole } & \multirow[t]{3}{*}{$\mathrm{R}$} & \multicolumn{4}{|c|}{${ }^{1} \mathrm{H}$ NMR signals of tautomeric forms $\mathbf{A}$ and $\mathbf{B}$ in DMSO- $d_{6}(0.1 \mathrm{M}), \mathrm{ppm}$} & \multirow[t]{3}{*}{$\mathrm{K}_{\mathrm{T}}$} & \multirow{3}{*}{$\begin{array}{l}-\Delta \mathrm{G}_{298} \\
\mathrm{~kJ} \mathrm{~mol}^{-1}\end{array}$} \\
\hline & & \multicolumn{2}{|c|}{$3(5)-\mathrm{NH}_{2}$} & \multicolumn{2}{|c|}{$\mathrm{N}(1)-\mathrm{H}$} & & \\
\hline & & A & B & A & B & & \\
\hline $2 a$ & $\mathrm{Ph}$ & 5.29 & 6.05 & 13.20 & 12.04 & 8.2 & 5.2 \\
\hline $2 \mathbf{b}$ & $4-\mathrm{MeC}_{6} \mathrm{H}_{4}$ & 5.25 & 6.01 & 13.09 & 11.96 & 6.1 & 4.4 \\
\hline 2c & $4-\mathrm{MeOC}_{6} \mathrm{H}_{4}$ & 5.21 & 5.99 & 12.99 & 11.90 & 5.0 & 4.0 \\
\hline $2 \mathbf{e}$ & $4-\mathrm{ClC}_{6} \mathrm{H}_{4}$ & 5.37 & 6.10 & 13.25 & 12.12 & 20.6 & 7.5 \\
\hline $2 f$ & 2-furyl & 5.29 & 6.07 & 13.20 & 12.07 & 13.6 & 6.5 \\
\hline $2 g$ & 2-thienyl & 5.34 & 6.09 & 13.16 & 12.02 & 22.9 & 7.8 \\
\hline $2 h$ & 2-pyridyl & 5.33 & 6.08 & 13.45 & 12.23 & 1.6 & 1.2 \\
\hline $2 \mathbf{i}$ & 3-pyridyl & 5.42 & 6.18 & 13.41 & 12.22 & 25.2 & 8.0 \\
\hline
\end{tabular}

The 1,2,4-triazoles 2 were found to exist in amino forms; imino forms were disfavored according to literature data. ${ }^{17}$ Of the three tautomeric forms theoretically possible due to annular tautomerism (Scheme 2), forms $\mathbf{A}$ and $\mathbf{B}$ were found to be present in the solutions of triazoles 2, while form $\mathbf{C}$ was not observed under the experimental conditions.

The equilibrium between the tautomers was established rapidly and the compositions did not change with time. The identical spectra of the tautomeric system A-B were observed instantaneously on dissolving the samples and after equilibration of the solution overnight.<smiles>[R]c1ccc(-c2n[nH]c(N)n2)cc1</smiles>

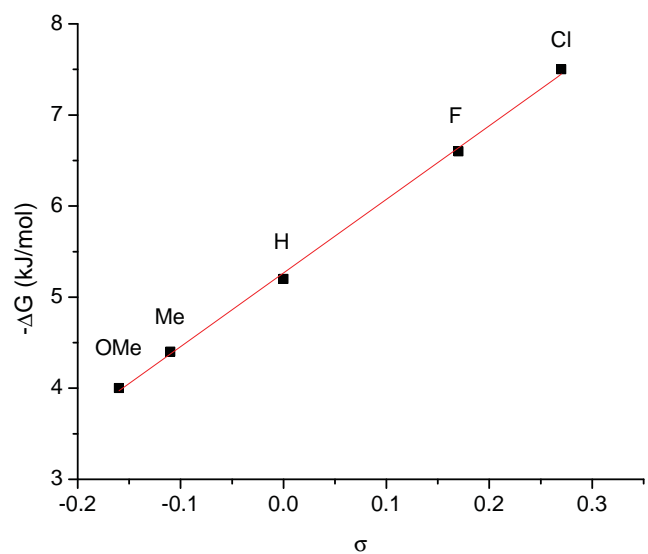

Figure 1. Correlation of $-\Delta \mathrm{G}$ for the tautomeric equilibrium of 3-amino-5aryl- and 5-amino-3-aryl-1,2,4-triazoles with the Hammett constant $(\sigma)$ of the R group.
The $\mathrm{NH}$ and $\mathrm{NH}_{2}$ signals of tautomers $\mathbf{A}$ and $\mathbf{B}$ in the ${ }^{1} \mathrm{H}$ NMR spectra in DMSO were quite distinct allowing calculation of $\mathrm{K}_{\mathrm{T}}$ values (Table 4). 5-Amino-1,2,4-triazoles B were identified to be the predominant tautomers. The substituent showed significant effects on the equilibrium between tautomeric forms A and B. This effect was strongly dependent on the electronic properties of the substituents. It was found that the $\mathrm{K}_{\mathrm{T}}$ and $\Delta \mathrm{G}_{298}$ values correlated well with the Hammett constant ${ }^{18}$ of the substituents on the phenyl ring of 2a-e: $-\Delta \mathrm{G}_{298}=$ $8.086 \sigma+5.265, \quad \mathrm{R}^{2}=0.998$ (Fig. 1). Therefore, the thermodynamic stability of form $\mathbf{B}$ in comparison with $\mathbf{A}$ increased together with the electron-withdrawing properties of the substituents. This relationship could also be extended to some heterocyclic, i.e. 3-pyridyl, 4-pyridyl and 2-thienyl substituents at C3(5) of the 1,2,4-triazole ring. However, experimental results for compounds $\mathbf{2 f}, \mathbf{h}$ with 2-furyl and especially 2-pyridyl substituents at these positions were outside this correlation. At first glance, this observation could be attributed to possible intramolecular hydrogen bonding between $\mathrm{N} 1-\mathrm{H}$ and the nitrogen atom of the pyridyl and the oxygen atom of the furyl moieties in form A. The intramolecular hydrogen bonding N1-H...X $(X=O$, $\mathrm{N})$ would prevent shifting of the tautomeric equilibrium towards "electronically" favored form $\mathbf{B}$ despite the strong electron-withdrawing effect of the heterocycles. However, this explanation became wide open to criticism by detail analysis of further experiments. The signals of N(1)-H in the ${ }^{1} \mathrm{H}$ NMR spectra appeared at the same range and had similar line widths for all triazoles 2. Increasing the concentration of the samples from 0.1 to $1.0 \mathrm{M}$ caused a $\sim 0.2$ ppm downfield shift of the signals (particularly $\mathrm{NH}$ and $\mathrm{NH}_{2}$ ) in the ${ }^{1} \mathrm{H}$ NMR spectra without affecting $\mathrm{K}_{\mathrm{T}}$. Heating the sample should disfavor systems stabilized by intramolecular hydrogen bonding and would shift the equilibrium to form B. However, no significant changes in 
$\mathrm{K}_{\mathrm{T}}$ were observed for $\mathbf{2 f}$,h at elevated temperatures, similarly to $\mathbf{2}$ without potential intramolecular hydrogen bonding. The signals of the tautomers $\mathbf{A}$ and $\mathbf{B}$ appeared clearly in NMR spectra in DMSO- $d_{6}$ solution and coalesced only on heating (Fig. 2). Interestingly, addition of nonpolar $\mathrm{CDCl}_{3}$ to the DMSO- $d_{6}$ solution of triazoles $\mathbf{2 f}, \mathbf{h}$ did not strengthen the intramolecular hydrogen bonding as expected. In contrast, the rate of the tautomeric exchange became too fast to be observed on the NMR time-scale. Only one set of signals appeared in the NMR spectra when a mixture of DMSO- $d_{6}$ and $\mathrm{CDCl}_{3}$ (1:1) was used as solvent for the experiment, as exemplified in Fig. 2. Therefore, the "anomalous" thermodynamic stability of tautomeric forms A for $\mathbf{2 f , h}$ as well as the effect of solvents on the rate of tautomeric exchange are still to be revealed.

Unsymmetric 3,5-disubstituted 1,2,4-triazoles have been known to crystallized in the form of tautomer bearing an electron-acceptor substituent at position 3 and an electrondonor substituent at position 5. ${ }^{19}$ Surprisingly, we found that the presence of forms $\mathbf{A}$ and $\mathbf{B}$ in the crystal was possible even for compounds bearing substituents with considerably different electronic properties. Thus, two compounds i.e. 5-amino-3-phenyl-1,2,4-triazole and 3amino-5-phenyl-1,2,4-triazole (2a) crystallized together in the same crystal (Fig. 3) despite the fact that the $\mathrm{K}_{\mathrm{T}}$ value for their equilibrium in $\mathrm{DMSO}-d_{6}$ solution was 8.2. Conversely, $2 \mathbf{h}$ with a $\mathrm{K}_{\mathrm{T}}$ in DMSO- $d_{6}$ solution equal to 1.6, crystallized solely as 5-amino-3-(pyridin-2-yl)-1,2,4triazole (form B) (Fig. 4).

In conclusion, an efficient and environmentally friendly method for the preparation of 3(5)-amino-1,2,4-triazoles has been developed and some aspects of the tautomerism in these compounds has been described.

\section{Acknowledgements}

This work is supported by the National Medical Research Council, Singapore (NMRC/NIG/0019/2008 and NMRC/NIG/0020/2008). The authors thank Koh Lip Lin and Tan Geok Kheng for the X-ray crystallography studies.

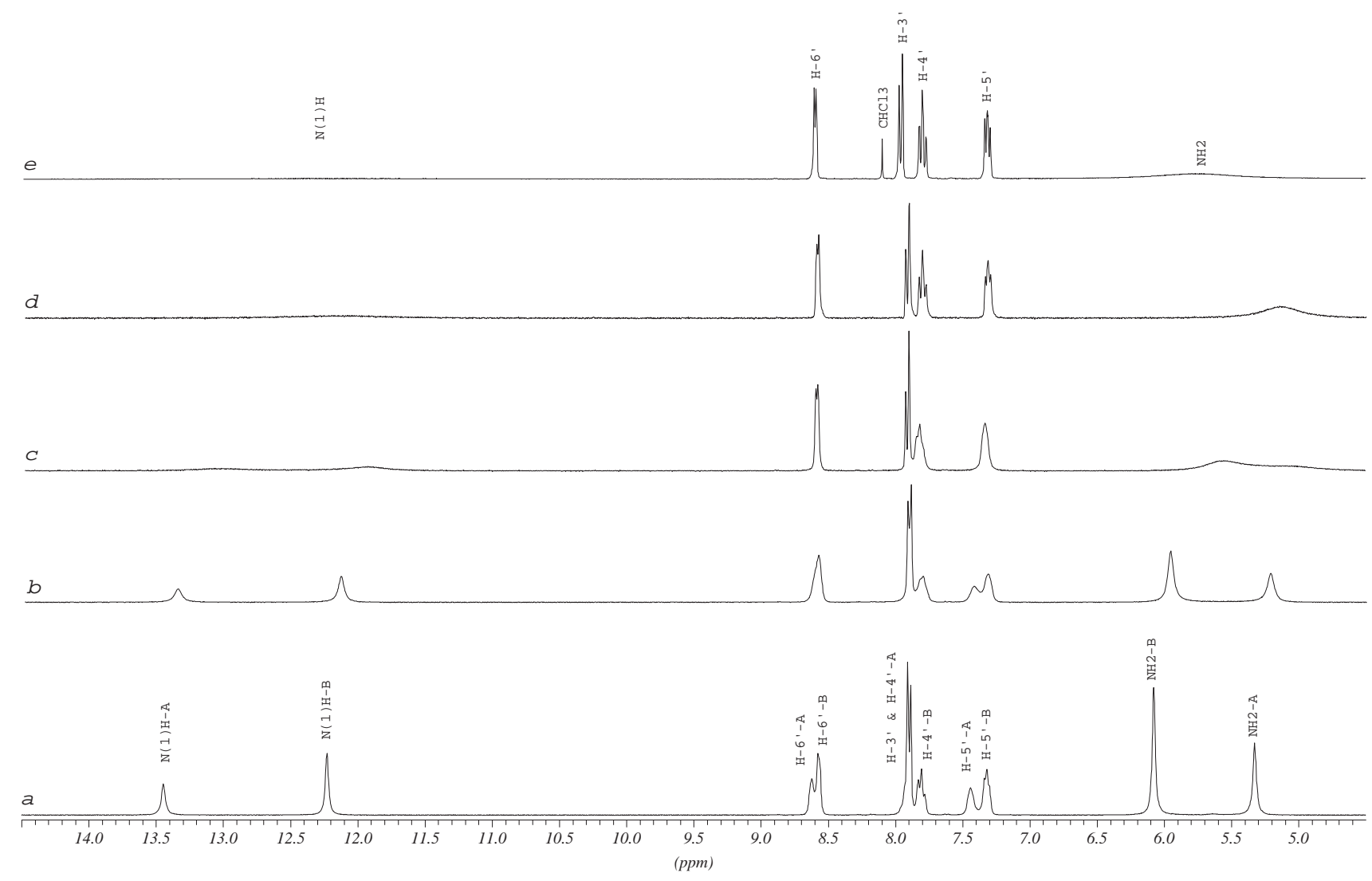

Figure 2. ${ }^{1} \mathrm{H}$ NMR spectra of 3(5)-amino-5(3)-(pyridin-2-yl)-1,2,4-triazole (2h) $0.1 \mathrm{M}$ solution in DMSO-d $6,27{ }^{\circ} \mathrm{C}(\mathrm{a}) ; 50{ }^{\circ} \mathrm{C}(\mathrm{b}) ; 100{ }^{\circ} \mathrm{C}(\mathrm{c}) ; 150{ }^{\circ} \mathrm{C}(\mathrm{d})$; $0.1 \mathrm{M}$ solution in DMSO- $d_{6}-\mathrm{CDCl}_{3}(1: 1), 27^{\circ} \mathrm{C}(\mathrm{e})$ 


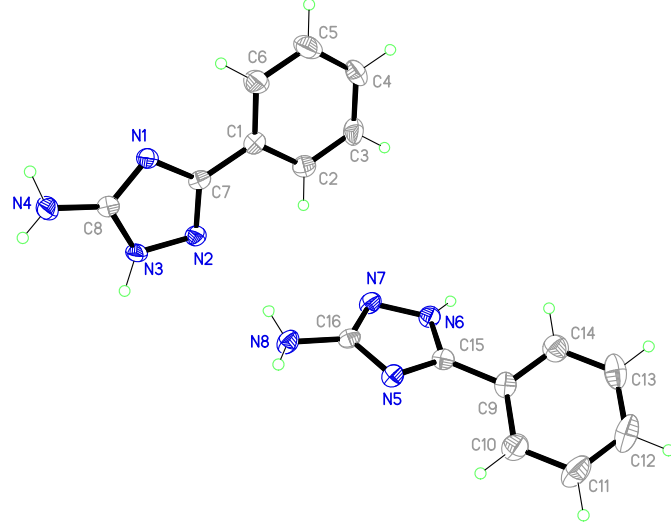

Figure 3. X-ray structure of $2 \mathbf{a}^{20}$

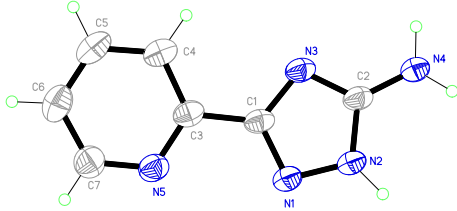

Figure 4. X-ray structure of $2 \mathbf{h}^{21}$

\section{References}

1. Al-Masoudi, I. A.; Al-Soud, Y. A.; Al-Salihi, N. J.; AlMasoudi, N. A. Chem. Heterocycl. Compd. 2006, 42, 13771404.

2. Haasnoot, J. G. Coord. Chem. Rev. 2000, 200-202, 131-185.

3. (a) Fischer, G. Adv. Heterocycl. Chem. 2008, 95, 143-219; (b) Yang, G.; Yang, H. Trends Heterocycl. Chem. 2003, 9, 109116; (c) Fischer, G. Adv. Heterocycl. Chem. 1993, 57, 81-138; (d) Fischer, G. Z. Chem. 1990, 30, 305-315.

4. Dolzhenko, A. V.; Dolzhenko, A. V.; Chui, W. K. Heterocycles 2006, 68, 1723-1759.

5. (a) Naito, Y.; Akahoshi, F.; Takeda, S.; Okada, T.; Kajii, M.; Nishimura, H.; Sugiura, M.; Fukaya, C.; Kagitani, Y. J. Med. Chem. 1996, 39, 3019-3029; (b) Lipinski, C. A. J. Med. Chem. 1983, 26, 1-6; (c) Grinstein, V.; Chipen, G. I. Zh. Obshch. Khim. 1961, 31, 886-890; (d) Biemann, K.; Bretschneider, H. Monatsh. Chem. 1958, 89, 603-610; (e) Hoggarth, E. J. Chem. Soc. 1950, 612-614.

6. (a) Katritzky, A. R.; Lagowski, J. M. Adv. Heterocycl. Chem. 1963, 18, 27-81; (b) Minkin, V. I.; Garnovskii, A. D.; Elguero, J.; Katritzky, A. R.; Denisko, O. V. Adv. Heterocycl. Chem. 2000, 76, 157-323.

7. (a) Karpinska, G.; Dobrowolski, J. C. THEOCHEM 2008, 853, 7-17; (b) Palmer, M. H.; Christen, D. J. Mol. Struct. 2004, 705, 177-187; (c) Oziminski, W. P.; Dobrowolski, J. C.; Mazurek, A. P. THEOCHEM 2004, 680, 107-115; (d) Oziminski, W. P.; Dobrowolski, J. C.; Mazurek, A. P. J. Mol. Struct. 2003, 651-653, 697-704; (e) Parchment, O. G.; Hillier, I. H.; Green, D. V. S.; Burton, N. A.; Morley, J. O.; Schaefer, H. F. J. Chem. Soc., Perkin Trans. 2 1992, 1681-1684.
8. (a) Hegarty, A. F.; O'Mahony, T. A. F.; Quain, P.; Scott, F. L. J. Chem. Soc., Perkin Trans. 2 1973, 2047-2054; (b) Caulkett, P. W. R.; Jones, G.; McPartlin, M.; Renshaw, N. D.; Stewart, S. K.; Wright, B. J. Chem. Soc., Perkin Trans. 1. 1995, 801808; (c) Atkinson, M. R.; Komzak, A. A.; Parkes, E. A.; Polya, J. B. J. Chem. Soc. 1954, 4508-4510.

9. Alfonsi, K.; Colberg, J.; Dunn, P. J.; Fevig, T.; Jennings, S.; Johnson, T. A.; Kleine, H. P.; Knight, C.; Nagy, M. A.; Perry, D. A.; Stefaniak, M. Green Chem. 2008, 10, 31-36.

10. (a) Hailes, H. C. Org. Process Res. Dev. 2007, 11, 114-120; (b) Li, C. J.; Chen, L. Chem. Soc. Rev. 2006, 35, 68-82; (c) Organic Reactions in Water: Principles, Strategies and Applications; Lindstroem, U. M., Ed.; Blackwell: Oxford, UK, 2007.

11. General procedure for the conventional synthesis of 3(5)amino-5(3)-het(aryl)-1,2,4-triazoles (2).

(Het)arylamidoguanidines (1) were heated under reflux in water (see Table 1 for volume and time). After cooling, the precipitated products 2 were filtered, washed with ice-cold water and dried. The purity of $\mathbf{2}$ was satisfactory; for analysis, the samples were recrystallized from water or aq. EtOH (2e,g). The reaction can be scaled up from 0.5 to $20 \mathrm{~g}$ without significant changes in the yields. 2a: ${ }^{1} \mathrm{H}$ NMR $(300 \mathrm{MHz}$, DMSO- $d_{6}$ ): $\delta 5.29 *$ and 6.05 (two s, $\left.2 \mathrm{H}, \mathrm{NH}_{2}\right), 7.32\left(\mathrm{t},{ }^{3} \mathrm{~J} 7.2\right.$ $\mathrm{Hz}, 1 \mathrm{H}, \mathrm{H}-4^{\prime}$ ), 7.39 (t, ${ }^{3} \mathrm{~J} 7.2 \mathrm{~Hz}, 2 \mathrm{H}, \mathrm{H}-3^{\prime}$ and -5 '), 7.89 (d, ${ }^{3} \mathrm{~J} 6.8 \mathrm{~Hz}, 2 \mathrm{H}, \mathrm{H}-2$ ' and -6'), 12.04 and $13.20^{*}$ (two s, $1 \mathrm{H}$, $\mathrm{NH}) ;{ }^{13} \mathrm{C}$ NMR (75 MHz, DMSO- $\left.d_{6}\right): \delta 125.4$ (C-3' and -5 '), 128.1 (C-4'), 128.3 (C-2' and -6'), 132.3 (C-1'), 152.4*, 157.3, 158.4 and $164.4^{*}$ (C-3 and -5). 2b: ${ }^{1} \mathrm{H}$ NMR (300 MHz, DMSO- $d_{6}$ ): $\delta 2.32$ (s, 3H, Me), 5.25* and 6.01 (two s, $\left.2 \mathrm{H}, \mathrm{NH}_{2}\right), 7.19$ (d, ${ }^{3} \mathrm{~J} 7.9 \mathrm{~Hz}, 2 \mathrm{H}, \mathrm{H}-3$ ' and -5 '), $7.77\left(\mathrm{~d},{ }^{3} \mathrm{~J}\right.$ $7.9 \mathrm{~Hz}, 2 \mathrm{H}, \mathrm{H}-2$ ' and -6'), 11.96 and $13.09^{*}$ (two s, 1H, NH); ${ }^{13} \mathrm{C}$ NMR (75 MHz, DMSO- $d_{6}$ ): $\delta 20.8(\mathrm{Me}), 125.4(\mathrm{C}-3$ ' and -5 '), 128.9 (C-2' and -6'), 129.6 (C-1'), 137.4 and 139.1* (C$\left.4^{\prime}\right), 152.5^{*}, 157.3,158.5$ and $164.2^{*}(\mathrm{C}-3$ and -5$) .2 \mathrm{c}:{ }^{1} \mathrm{H}$ NMR (300 MHz, DMSO- $\left.d_{6}\right): \delta 3.78$ (s, 3H, OMe), 5.21* and 5.99 (two s, $\left.2 \mathrm{H}, \mathrm{NH}_{2}\right), 6.95$ (d, ${ }^{3} \mathrm{~J} 8.7 \mathrm{~Hz}, 2 \mathrm{H}, \mathrm{H}-3$ ' and -5 '), $7.81\left(\mathrm{~d},{ }^{3} \mathrm{~J} 8.7 \mathrm{~Hz}, 2 \mathrm{H}, \mathrm{H}-2\right.$ ' and -6 '), 11.90 and $12.99^{*}$ (two $\mathrm{s}, 1 \mathrm{H}, \mathrm{NH}) ;{ }^{13} \mathrm{C}$ NMR $\left(75 \mathrm{MHz}, \mathrm{DMSO}-d_{6}\right): \delta 55.0(\mathrm{OMe})$, 113.8 (C-3' and -5'), 125.0 (C-1'), 126.8 (C-2' and -6'), $152.3 *, 157.2,158.4$ and $164.2^{*}(\mathrm{C}-3$ and -5$), 159.4$ and $160.1^{*}\left(\mathrm{C}-4\right.$ '). 2d: ${ }^{1} \mathrm{H}$ NMR (300 MHz, DMSO-d $\left.d_{6}\right): \delta 5.31^{*}$ and 6.04 (two s, $\left.2 \mathrm{H}, \mathrm{NH}_{2}\right), 7.22\left(\mathrm{dd},{ }^{3} J 8.7,{ }^{3} J_{\mathrm{HF}} 8.7 \mathrm{~Hz}, 2 \mathrm{H}\right.$, H-3' and -5'), 7.91 (dd, ${ }^{3} J$ 8.7, ${ }^{4} J_{\mathrm{HF}} 5.7 \mathrm{~Hz}, 2 \mathrm{H}, \mathrm{H}-2$ ' and -6'), 12.05 and $13.18^{*}$ (two s, $\left.1 \mathrm{H}, \mathrm{NH}\right) ;{ }^{13} \mathrm{C}$ NMR $(75 \mathrm{MHz}$, DMSO- $\left.d_{6}\right): \delta 115.2\left(\mathrm{~d},{ }^{2} J_{\mathrm{CF}} 22.3 \mathrm{~Hz}, \mathrm{C}-3\right.$ ' and -5 ') $127.2(\mathrm{~d}$, ${ }^{3} J_{\mathrm{CF}} 8.2 \mathrm{~Hz}, \mathrm{C}-2$ ' and -6'), $128.9\left(\mathrm{~d},{ }^{4} J_{\mathrm{CF}} 2.9 \mathrm{~Hz}, \mathrm{C}-1\right.$ '), 157.3 and $157.5(\mathrm{C}-3$ and -5$), 162.1\left(\mathrm{~d},{ }^{1} J_{\mathrm{CF}} 244.6 \mathrm{~Hz}, \mathrm{C}-4\right.$ '). 2e: ${ }^{1} \mathrm{H}$ NMR (300 MHz, DMSO- $\left.d_{6}\right): \delta 5.37 *$ and 6.10 (two s, $2 \mathrm{H}$, $\left.\mathrm{NH}_{2}\right), 7.46\left(\mathrm{~d},{ }^{3} J 8.3 \mathrm{~Hz}, 2 \mathrm{H}, \mathrm{H}-3\right.$ ' and -5 '), $7.88\left(\mathrm{~d},{ }^{3} J 8.3\right.$ $\mathrm{Hz}, 2 \mathrm{H}, \mathrm{H}-2^{\prime}$ and $-6^{\prime}$ ), 12.12 and $13.25^{*}$ (two s, $\left.1 \mathrm{H}, \mathrm{NH}\right) ;{ }^{13} \mathrm{C}$ NMR (75 MHz, DMSO-d 6 ): $\delta 126.9$ (C-3' and -5'), 128.4 (C2' and -6'), 131.2 (C-1'), 132.6 (C-4'), 157.4 (C-3 and -5). 2f: ${ }^{1} \mathrm{H}$ NMR (300 MHz, DMSO-d 6 ): $\delta 5.29^{*}$ and 6.07 (two s, $2 \mathrm{H}$, $\left.\mathrm{NH}_{2}\right), 6.54$ (dd, ${ }^{3} J 3.0$ and $1.5 \mathrm{~Hz}, 1 \mathrm{H}, \mathrm{H}-4$ '), $6.67\left(\mathrm{~d},{ }^{3} J 3.0\right.$ $\mathrm{Hz}, 1 \mathrm{H}, \mathrm{H}-3$ '), 7.68 (d, $\left.{ }^{3} \mathrm{~J} 1.5 \mathrm{~Hz}, 1 \mathrm{H}, \mathrm{H}-5^{\prime}\right), 12.07$ and $13.20 *$ (two s, $1 \mathrm{H}, \mathrm{NH}) ;{ }^{13} \mathrm{C}$ NMR (75 MHz, DMSO- $\left.d_{6}\right): \delta$ 107.4 (C-4' ), 111.2 (C-3’), 142.5 (C-5'), 147.6 (C-2'), 152.1 and 156.9 (C-3 and -5). 2g: ${ }^{1} \mathrm{H}$ NMR (300 MHz, DMSO- $d_{6}$ ): $\delta 5.34^{*}$ and 6.09 (two s, $2 \mathrm{H}, \mathrm{NH}_{2}$ ), 7.07 (dd, ${ }^{3} \mathrm{~J} 4.9$ and 3.4 $\mathrm{Hz}, 1 \mathrm{H}, \mathrm{H}-4^{\prime}$ ), 7.40 (d, ${ }^{3} \mathrm{~J} 3.0 \mathrm{~Hz}, 1 \mathrm{H}, \mathrm{H}-3^{\prime}$ ), 7.46 (d, ${ }^{3} \mathrm{~J} 4.9$ $\mathrm{Hz}, 1 \mathrm{H}, \mathrm{H}-5$ ') 12.02 and $13.16^{*}$ (two s, $\left.1 \mathrm{H}, \mathrm{NH}\right) ;{ }^{13} \mathrm{C} \mathrm{NMR}$ (75 MHz, DMSO-d $d_{6}$ ): $\delta 124.2$ (C- 4'), 125.4 (C-5'), 127.4 (C3' ), 135.5 (C-2'), 154.7 and 157.1 (C-3 and -5). 2h: ${ }^{1} \mathrm{H}$ NMR $\left(300 \mathrm{MHz}, \mathrm{DMSO}-d_{6}\right): \delta 5.33 *$ and 6.08 (two $\mathrm{s}, 2 \mathrm{H}, \mathrm{NH}_{2}$ ), 7.25-7.51 (m, 1H, H-5'), 7.74-8.00 (m, 2H, H-3' and -4'), 8.52-8.69 (m, 1H, H-6'), 12.23 and 13.45* (two s, $1 \mathrm{H}, \mathrm{NH}$ ); 
${ }^{13} \mathrm{C}$ NMR (75 MHz, DMSO- $\left.d_{6}\right): \delta 120.7^{*}$ and 120.9 (C-5'), 123.0 and $124.3^{*}\left(\mathrm{C}^{\prime} 3^{\prime}\right), 136.5$ and $137.5^{*}\left(\mathrm{C}-4^{\prime}\right), 146.5^{*}$ and 150.7 (C-2'), 149.2 (C-6'), 151.6*, 157.2, 158.6 and 164.4* $(\mathrm{C}-3$ and -5$) .2 \mathbf{i}:{ }^{1} \mathrm{H}$ NMR (300 MHz, DMSO- $\left.d_{6}\right): \delta 5.42 *$ and 6.18 (two s, $2 \mathrm{H}, \mathrm{NH}_{2}$ ), 7.43 (dd, ${ }^{3} \mathrm{~J} 7.5$ and $4.9 \mathrm{~Hz}, 1 \mathrm{H}, \mathrm{H}-5$ '), 8.18 (dt, ${ }^{3} J 7.9,{ }^{4} J 1.7 \mathrm{~Hz}, 1 \mathrm{H}, \mathrm{H}-4$ '), 8.54 (dd, ${ }^{3} \mathrm{~J} 4.2,{ }^{4} \mathrm{~J} 1.5$ $\mathrm{Hz}, 1 \mathrm{H}, \mathrm{H}-6$ '), 9.06 (d, $\left.{ }^{4} \mathrm{~J} 1.5 \mathrm{~Hz}, 1 \mathrm{H}, \mathrm{H}-2^{\prime}\right), 12.22$ and $13.41^{*}($ two s, $1 \mathrm{H}, \mathrm{NH}) ;{ }^{13} \mathrm{C}$ NMR $\left(75 \mathrm{MHz}, \mathrm{DMSO}_{6}\right): \delta$ 123.6 (C-5'), 127.9 (C-3'), 132.4 (C-4'), 146.5 (C-2'), 149.0 (C-6'), 156.1 and 157.5 (C-3 and -5). 2j: ${ }^{1} \mathrm{H}$ NMR (300 MHz, DMSO- $d_{6}$ ): $\delta 5.48^{*}$ and 6.22 (two s, $2 \mathrm{H}, \mathrm{NH}_{2}$ ), $7.78\left(\mathrm{dd},{ }^{3} \mathrm{~J}\right.$ $4.5,{ }^{4} \mathrm{~J} 1.5 \mathrm{~Hz}, 2 \mathrm{H}, \mathrm{H}-3$ ' and -5 '), 8.60 (d, ${ }^{3} \mathrm{~J} 5.7 \mathrm{~Hz}, 2 \mathrm{H}, \mathrm{H}-2$ ' and $\left.-6^{\prime}\right), 12.35$ and $13.64 *$ (two s, $\left.1 \mathrm{H}, \mathrm{NH}\right) ;{ }^{13} \mathrm{C}$ NMR (75 MHz, DMSO- $\left.d_{6}\right): \delta 119.5$ (C-3' and -5'), 139.2 (C-4'), 149.9 (C-2' and -6'), 156.4 and 157.6 (C-3 and -5). *- signals of minor tautomers $\mathbf{A}$.

12. (a) Jindal, R.; Bajaj, S. Curr. Org. Chem. 2008, 12, 836-849; (b) Polshettiwar, V.; Varma, R. S. Pure Appl. Chem. 2008, 80, 777-790; (c) El Ashry, E. S. H.; Kassem, A. A.; Ramadan, E. Adv. Heterocycl. Chem. 2008, 90, 1-123; (d) Shipe, W. D.; Yang, F.; Zhao, Z.; Wolkenberg, S. E.; Nolt, M. B.; Lindsley, C. W. Heterocycles 2006, 70, 655-689; (e) Suna, E.; Mutule, I. Top. Curr. Chem. 2006, 266, 49-101; (f) El Ashry, E. S. H.; Ramadan, E.; Kassem, A. A.; Hagar, M. Adv. Heterocycl. Chem. 2005, 88, 1-110.

13. (a) Kahveci, B.; Ozil, M.; Serdar, M. Heteroat. Chem. 2008, 19, 38-42; (b) Katritzky, A. R.; Khashab, N. M.; Kirichenko, N.; Singh, A. J. Org. Chem. 2006, 71, 9051-9056; (c) Wu, D. Q.; He, J. L.; Wang, J. K.; Wang, X. C.; Zong, Y. X. J. Chem. Res. 2006, 293-294; (d) Zamani, K.; Bagheri, S. Phosphorus, Sulfur Silicon Relat. Elem. 2006, 181, 1913-1918; (e) Li, D.; Bao, H.; You, T. Heterocycles 2005, 65, 1957-1962; (f) Yeung, K. S.; Farkas, M. E.; Kadow, J. F.; Meanwell, N. A. Tetrahedron Lett. 2005, 46, 3429-3432; (g) Rostamizadeh, S.; Tajik, H.; Yazdanfarahi, S. Synth. Commun. 2003, 33, 113117; (h) Koshima, H.; Hamada, M.; Tani, M.; Iwasaki, S.;
Sato, F. Heterocycles 2002, 57, 2145-2148; (i) Woisel, P.; Cazier, F.; Surpateanu, G.; Baudel, V.; Boursier, V. Heterocycl. Commun. 2002, 8, 71-74; (j) Kidwai, M.; Misra, P.; Bhushan, K. R.; Dave, B. Synth. Commun. 2000, 30, 3031-3040; (k) Bentiss, F.; Lagrenee, M.; Barbry, D. Tetrahedron Lett. 2000, 41, 1539-1541.

14. (a) Polshettiwar, V.; Varma, R. S. Chem. Soc. Rev. 2008, 37, 1546-1557; (b) Polshettiwar, V.; Varma, R. S. Acc. Chem. Res. 2008, 41, 629-639; (c) Dallinger, D.; Kappe, C. O. Chem. Rev. 2007, 107, 2563-2591.

15. General procedure for the microwave synthesis of 3(5)amino-5(3)-het(aryl)-1,2,4-triazoles (2).

(Het)arylamidoguanidines $(\mathbf{1}, 1 \mathrm{mmol})$ were irradiated in $3 \mathrm{ml}$ of water using a CEM "Discover" microwave apparatus, (see Tables 2 and 3 for power and time). After cooling, the precipitated products 2 were filtered, washed with ice-cold water and dried.

16. (a) Claramunt, R. M.; Lopez, C.; Santa Maria, M. D.; Sanz, D.; Elguero, J. Prog. Nucl. Magn. Reson. Spectrosc. 2006, 49, 169-206; (b) Kleinpeter, E. Adv. Mol. Struct. Res. 2000, 6, 97-129; (c) Elguero, J.; Katritzky, A. R.; Denisko, O. V. Adv. Heterocycl. Chem. 2000, 76, 1-84.

17. Curtis, A. D. M. Sci. Synth. 2004, 13, 603-639.

18. We used the Hammett constant values from: Hansch, C.; Leo, A.; Taft, R. W. Chem. Rev. 1991, 91, 165-195.

19. Buzykin, B. I.; Mironova, E. V.; Nabiullin, V. N.; Gubaidullin, A. T.; Litvinov, I. A. Russ. J. Gen. Chem. 2006, 76, 1471-1486.

20. Dolzhenko, A. V.; Tan, G. K.; Koh, L. L.; Dolzhenko, A. V.; Chui, W. K. Acta Cryst. 2009, E65, o126 (doi:10.1107/S1600536808042165).

21. Dolzhenko, A. V.; Tan, G. K.; Koh, L. L.; Dolzhenko, A. V.; Chui, W. K. Acta Cryst. 2009, E65, o125 (doi:10.1107/S1600536808042177). 